\title{
Suppression of $\beta$-catenin Signaling Pathway in Human Prostate Cancer PC3 Cells by Delphinidin
}

SHORT

COMMUNICATION

\author{
Wooje Lee ${ }^{1}$, Jung-Mi Yun ${ }^{2}$ \\ ${ }^{1}$ National Research Center for Dementia, Chosun University, ${ }^{2}$ Division of Food and Nutrition, Chonnam National University, Gwangju, Korea
}

\begin{abstract}
Delphinidin possesses strong anti-oxidant, anti-inflammatory, and anti-cancer properties. Suppression of the Wnt/ $\beta$-catenin signaling pathway is a potential strategy for chemoprevention and therapy. As aberrant activation of the $\beta$-catenin signaling pathway contributes to prostate cancer progression, we evaluated the effect of delphinidin on this pathway in human PC3 prostate cancer cells. An MTT assay showed that treatment with delphinidin (15-180 $\mu \mathrm{M}, 72$ hours) resulted in a dose-dependent growth inhibition of cells. Treatment with delphinidin increased the phosphorylation of serine or threonine residues on $\beta$-catenin and decreased the levels of cytoplasmic $\beta$-catenin. Moreover, treatment with delphinidin inhibited the nuclear translocation of $\beta$-catenin and the expression of $\beta$-catenin target genes such as cyclin D1, c-myc, Axin-2, and T cell factor-1. Delphinidin also induced the phosphorylation of glycogen synthase kinase $3 \beta$ and the expression of adenomatous polyposis coli and Axin proteins. Our results indicate that inhibition of cell growth by delphinidin is mediated, at least in part, through modulation of the $\beta$-catenin signaling pathway. We suggest that delphinidin is a potent inhibitor of Wnt/ $\beta$-catenin signaling in prostate cancer cells.
\end{abstract}

(J Cancer Prev 2016;21:110-114)

Key Words: Beta-catenin, Prostate neoplasms, Delphinidin, Anthocyanidins

\section{INTRODUCTION}

Prostate cancer is a major health problem and the fifth most prevalent disease condition among men in the world. Clinically, prostate cancer is commonly detected in men over fifty years of age. ${ }^{1}$ Considerable effort is currently being directed toward evaluating the usefulness of natural dietary agents for chemoprevention as well as chemotherapy of prostate cancer. Thus, interventions using cancer-chemopreventive compounds such as polyphenol dietary agents may prevent or retard the progression of this disease. ${ }^{2.3}$

In recent years, inhibition of the Wnt/ $\beta$-catenin signaling pathway has been an attractive target in the development of new chemopreventive and chemotherapeutic agents. The Wnt signaling pathway is involved in multiple developmental events during embryogenesis and has been implicated in adult tissue homeostasis and tumorigenesis. ${ }^{4}$ Moreover, the Wnt/ $/$-catenin signaling pathway regulates cellular functions related to tumor initiation and progression, cell proliferation, differentiation, survival, and adhesion. ${ }^{5}$ Therefore, dysregulation of $\beta$-catenin has been associated with the progression of prostate cancer.

In normal cells, free cytosolic $\beta$-catenin is rapidly phosphorylated by a multiprotein complex that includes adenomatous polyposis coli (APC), axin/conductin, and glycogen synthase kinase $3 \beta$ (GSK3 $\beta$ ). In addition, $\beta$-catenin along with E-cadherin functions as a critical component of the cell membrane and the adherence junction to enhance cell-cell adhesions. However, the binding of a Wnt ligand to the frizzled and lipoprotein receptor-related 5/6 proteins activates or dephosphorylates axin. This dephosphorylation decreases the capacity of axin to form complexes with APC and $\beta$-catenin. Phosphorylation by GSK3 $\beta$, and thus degradation of $\beta$-catenin by ubiquitin, is decreased. The

Received February 29, 2016, Revised June 9, 2016, Accepted June 9, 2016

Correspondence to: Jung-Mi Yun

Division of Food and Nutrition, Chonnam National University, 77 Yongbong-ro, Buk-gu, Gwangju 61186, Korea

Tel: +82-62-530-1332, Fax: +82-62-530-1339, E-mail: sosung75@gmail.com, ORCID: Jung-Mi Yun, http://orcid.org/0000-0001-6044-0647

Copyright (c) 2016 Korean Society of Cancer Prevention

(c) This is an Open Access article distributed under the terms of the Creative Commons Attribution Non-Commercial License (http://creativecommons.org/licenses/by-nc/4.0) which permits unrestricted non-commercial use, distribution, and reproduction in any medium, provided the original work is properly cited. 
aberrant activation of the Wnt pathway results in cytoplasmic accumulation of $\beta$-catenin and the nuclear translocation of $\beta$-catenin. In the nucleus, $\beta$-catenin binds to T-cell factor (TCF) and lymphoid enhancer factor (LEF) family and functions as a co-activator of target gene transcription. Tumors showing $\beta$-catenin accumulation are generally associated with a poorly differentiated form, high proliferation, vascular invasion, and dismal prognosis. ${ }^{4}$ Therefore, developing various effective agents that can inhibit the Wnt/ $\beta$-catenin signaling pathway may be a promising strategy for treating prostate cancer.

During the last few decades, natural dietary compounds have attracted increased attention among the scientific community due to their efficacy against various human cancers. Several natural dietary compounds such as curcumin, epigallocatechin-3-gallate, genistein, resveratrol, lycopene, and sulforaphane have drawn attention because of their ability to suppress cancers by inhibiting the Wnt/ $\beta$-catenin signaling pathway. ${ }^{5.6}$ Delphinidin, a major anthocyanidin present in many pigmented fruits and vegetables, exhibits antioxidant, anti-inflammatory, and anticancer properties. ${ }^{7,8}$ Despite the promising antitumor actions of delphinidin, the molecular mechanisms of these effects are generally unknown in prostate cancer. The findings of the present study suggest that delphinidin has the potential to be developed into a new inhibitor of the Wnt/ $\beta$-catenin signaling pathway in human prostate cancer.

\section{MATERIALS AND METHODS}

\section{Plant material and chemicals}

All antibodies were procured from Santa Cruz Biotechnology Inc. (Santa Cruz, CA, USA). Delphinidin was purchased from Extrasynthase (Lyon, France). All other chemicals, unless otherwise stated, were obtained from Sigma Aldrich (St. Louis, MO, USA).

\section{Cell culture}

The human prostate carcinoma cell line PC3 was obtained from the American Type Culture Collection (ATCC, Manassas, VA, USA). PC3 cells were cultured in an RPMI medium (ATCC) containing $10 \% \mathrm{FBS}, 100 \mathrm{U} / \mathrm{mL}$ of penicillin, and $100 \mu \mathrm{g} / \mathrm{mL}$ of streptomycin (Gibco/BRL, Grand Island, NY, USA). Cells were maintained at $37^{\circ} \mathrm{C}$ in a humidified atmosphere containing $5 \%$ $\mathrm{CO}_{2}$. Delphinidin was dissolved in dimethylsulfoxide (DMSO) and the final concentration of DMSO used in the cell culture was $0.1 \%(\mathrm{v} / \mathrm{v})$.

\section{MTT assay for cellular viability}

Cell viability was determined using the MTT (3-[4,5-dimethylthiazol-2-yl]-2,5-diphenyltetrazolium bromide; Sigma Aldrich) assay. The cells were plated at a density of $1 \times 10^{4}$ cells per well with $200 \mathrm{~mL}$ of complete culture medium and treated with various concentrations of delphinidin in 96-well microtiter plates for 72 hours. Each concentration of delphinidin $(15-240 \mu \mathrm{M})$ was repeated in 10 wells. After incubating the cells for the specified times at $37^{\circ} \mathrm{C}$ in a humidified incubator, an MTT reagent $(50 \mu \mathrm{L}$, $2 \mathrm{mg} / \mathrm{mL}$ in PBS) was added to each well and incubated for 2 hours. The microtiter plate containing the cells was centrifuged at $1,800 \mathrm{rpm}$ for 5 minutes at $4^{\circ} \mathrm{C}$. The MTT solution was removed from the wells by aspiration and the formazan crystals were dissolved in DMSO (150 $\mu \mathrm{L})$. Absorbance was recorded on a microplate reader at a wavelength of $570 \mathrm{~nm}$. The effect of delphinidin on growth inhibition was measured as the percentage of cell growth inhibition, while vehicle-treated cells were considered as $100 \%$ viable. $\mathrm{IC}_{50}$ values were determined from three independent experiments.

\section{Protein extraction and Western blot analysis}

Following treatment of the cells with delphinidin, the medium was aspirated and the cells were washed with cold PBS (10 nM; pH 7.45). The cells were then incubated in ice-cold lysis buffer $(50$ $\mathrm{mM}$ Tris- $\mathrm{HCl}, 150 \mathrm{mM} \mathrm{NaCl}, 1 \mathrm{mM}$ EGTA, $1 \mathrm{mM}$ EDTA, $20 \mathrm{mM}$ $\mathrm{NaF}, 100 \mathrm{mM} \mathrm{Na} \mathrm{VO}_{4}, 0.5 \% \mathrm{NP} 40,1 \%$ Triton X-100, $1 \mathrm{mM}$ phenylmethylsulfonyl fluoride; $\mathrm{pH}$ 7.4), with freshly added protease inhibitor cocktail (protease inhibitor cocktail set Ш; Calbiochem, La Jolla, CA, USA), and incubated on ice for 20 minutes. The cells were scraped and the lysate was collected in a microfuge tube and passed through a 21.5-gauge needle to break up the cell aggregates. The lysate was cleared by centrifugation at $13,000 \times g$ for 15 minutes at $4^{\circ} \mathrm{C}$, and the supernatant (total cell lysate) was collected, aliquoted, and used on the day of preparation or immediately stored at $-80^{\circ} \mathrm{C}$ until use. For Western blot analysis, $40 \mu \mathrm{g}$ of protein was resolved over $12 \%$ polyacrylamide gel and transferred onto a nitrocellulose membrane. Nonspecific sites on the blots were blocked by incubating the membrane in blocking buffer (5\% nonfat dry milk, 1\% Tween 20 in 20 mM TBS [pH 7.6]) for 1 hour at room temperature prior to incubation with appropriated mono- and poly-clonal primary antibodies in blocking buffer for 90 minutes overnight at $4^{\circ} \mathrm{C}$, followed by incubation with an anti-mouse or an anti-rabbit horseradish peroxidase-conjugated secondary antibody. Immunoreactivity bands were developed using the ECL System (Amersham Life 
Science, Little Chalfont, UK) and analyzed using the ChemiDoc MP imaging system (Bio-Rad, Hercules, CA, USA).

\section{Statistical analysis}

Each experiment was performed at least three. The results are expressed as the mean value $\pm \mathrm{SD}$. The significance of differences between groups was determined by applying one-way analysis of variance (ANOVA; SPSS ver. 16.0 software; SPSS Inc., Chicago, IL, USA) following Dunnett's $t$-test. Statistical significance is expressed as $* P<0.05, * * P<0.01$.

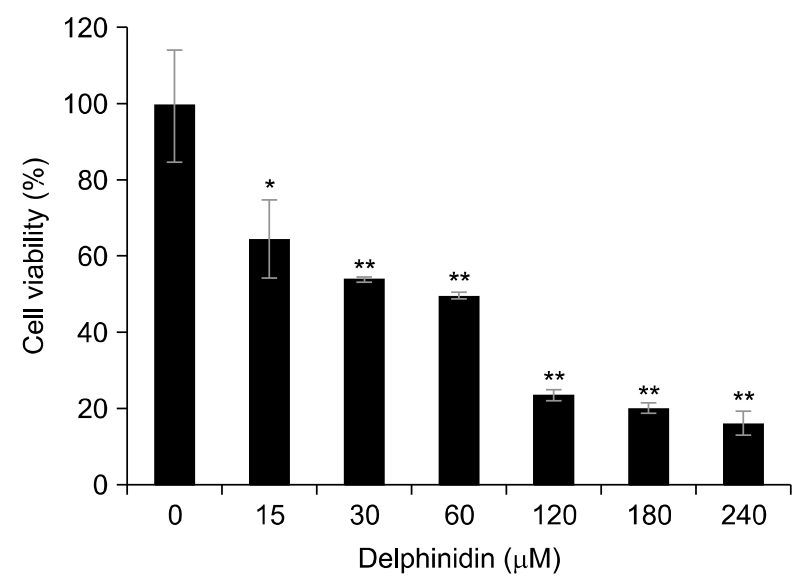

Figure 1. Effect of delphinidin on the viability of androgen-independent prostate cancer cells PC3. Cells were treated with specified concentrations of delphinidin for 72 hours, and cell viability was evaluated by MTT assay as described in Materials and Methods. The values are shown as a percentage of cell inhibition while vehicle treated cells were regarded as $100 \%$ viability. Results are shown as mean $\pm \mathrm{SD}$ of three different experiments. $* P<0.05$ and $* * P<$ 0.01 vs. control.

\section{RESULTS}

\section{Delphinidin suppresses the growth of PC3 cells}

To examine the effect of delphinidin on the viability of PC3 cells, we performed an MTT assay. Delphinidin treatment (15-240 $\mu \mathrm{M}, 72$ hours) dose-dependently inhibited cell growth (Fig. 1).

\section{Delphinidin inhibits $W n t / \beta$-catenin signaling and its target proteins in PC3 cells}

To understand the underlying mechanism by which delphinidin inhibits the growth of PC3 cells, we evaluated the effect of delphinidin on the expression levels of $\beta$-catenin and its target proteins. Western blot analysis revealed a significant increase in the phosphorylation of $\beta$-catenin on Ser45 and Ser33/37/Thr41 residues in cells treated with delphinidin, with a concomitant decrease in $\beta$-catenin in the cytoplasm and nucleus of cells (Fig. 2A). Additionally, delphinidin treatment significantly and dose-dependently decreased the expression of $\beta$-catenin target proteins such as Axin 2, cyclin D1, c-myc, TCF1, and LEF1 in the cells (Fig. 2B).

\section{Delphinidin increases the expression level of $\beta$-catenin destruction complex in PC3 cells}

The $\beta$-catenin destruction complex plays a critical role in maintaining low levels of $\beta$-catenin in the absence of an exogenous Wnt signal. Cytoplasmic $\beta$-catenin levels are typically maintained at low levels through continuous degradation by a destructive complex. ${ }^{4}$ We conducted Western blotting to determine the expression levels of essential proteins such as casein kinase 1 (CK1), protein phosphatase 2A (PP2A), GSK3, $\beta$-Trcp, Axin, and APC in the core complex (Fig. 3). We observed that
A

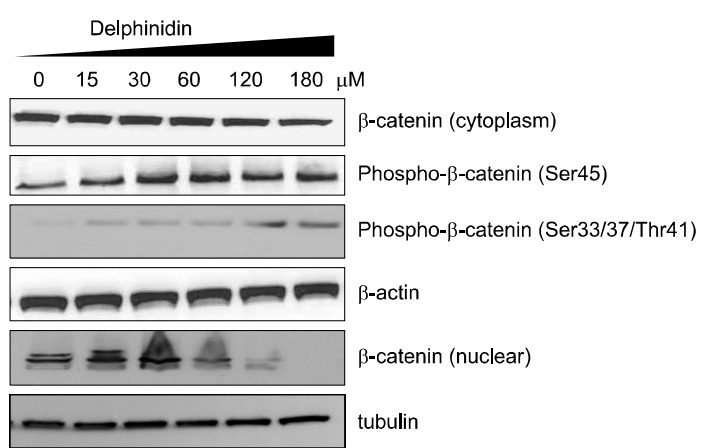

B

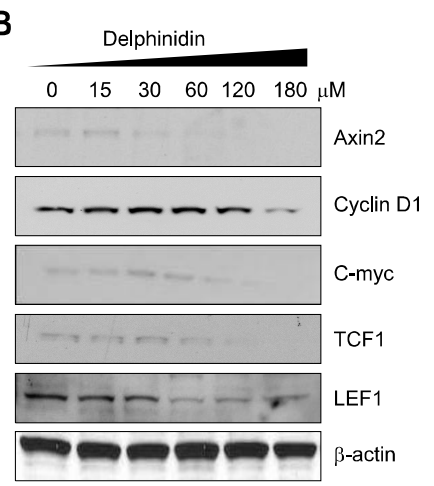

Figure 2. Effect of delphinidin on Wnt/ $\beta$-catenin signaling and its target proteins. Cells were treated with specified concentrations of delphinidin for 72 hours and harvested, after which total cell lysates were prepared. (A) Protein levels were evaluated by Western blot analysis for $\beta$-catenin and phospo- $\beta$-catenin. (B) The expression of Axin 2, cyclin D1, c-myc, T-cell factor 1 (TCF1), and lymphoid enhancer factor 1 (LEF1) were determined by Western blot analysis. Equal loading of proteins was confirmed by stripping the immunoblot and reprobing it for $\beta$-actin and tubulin. The immunoblots shown here are representative of three independent experiments. 
delphinidin treatment significantly and dose-dependently decreased the expressions of phospho-GSK3, PP2A, and $\beta$-Trcp, and increased the expression of truncated APC, Axin, and CK1. Thus, Delphinidin potently suppressed, at least in part, the $\beta$-catenin signaling pathway by increasing expression of the $\beta$-catenin destruction complex in PC3 cells.

\section{Effect of delphinidin on expression of E-cadherin in PC3 cells}

The E-cadherin/ $\beta$-catenin complex performs an important function in stabilizing $\beta$-catenin in the cell membrane while a disruption of this complex induces nuclear translocation of $\beta$-catenin. ${ }^{9}$ As shown in Figure 4 , we also observed that treating cells with delphinidin significantly and dose-dependently increased the expression level of E-cadherin. Therefore, our results suggest that delphinidin effectively suppressed prostate cancer growth in PC3 cells, at least in part, by blocking $\beta$-catenin signaling.

\section{DISCUSSION}

Prostate cancer has become a major health problem in the industrialized world, particularly during the last decades of the 20th century. ${ }^{1,2}$ Recently, plant-derived dietary agents have been shown to have therapeutic activity against various diseases and

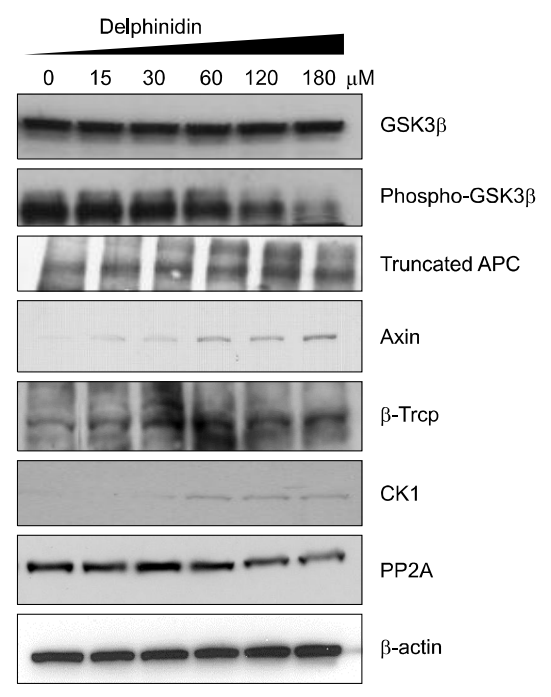

Figure 3. Effect of delphinidin on the expression of $\beta$-catenin destruction complex in PC3. Cells were treated with specified concentrations of delphinidin for 72 hours and harvested, after which total cell lysates were prepared. Protein levels were evaluated by Western blotting for casein kinase 1 (CK1), protein phosphatase 2A (PP2A), glycogen synthase kinase 3 (GSK3), Axin, and adenomatous polyposis coli (APC). Equal loading of proteins was confirmed by stripping the immunoblot and reprobing it for $\beta$-actin. The immunoblots shown here are representative of three independent experiments. conditions such as cancer. Hence, they have been suggested as promising alternative options. Recently, control of $\beta$-catenin signaling was suggested as a possible mechanism of chemopreventive therapies/agents. Several natural dietary agents, including genistein, curcumin, epigallocatechin gallate, resveratrol, lycopene, and sulforaphane have been directly evaluated and found to have the ability to regulate aberrant Wnt/ $\beta$-catenin signaling. ${ }^{5}$ Delphinidin has been reported to possess a variety of biological effects, including anti-inflammatory, anticancer, and anti-oxidant properties, ${ }^{7}$ albeit little is known about the molecular mechanisms of delphinidin's properties in experimental carcinogenesis. There is convincing evidence that aberrant activation of the $\mathrm{Wnt} / \beta$-catenin signaling is involved in the development and progression of several cancers. Therefore, suppression of Wnt/ $\beta$-catenin signaling may be useful in cancer treatment. A recent study showed that delphinidin induced apoptosis and cell cycle arrest in highly metastatic human prostate cancer PC3 and 22Rnul cells. ${ }^{8}$ Despite these promising actions of delphinidin, the molecular mechanisms underlying these effects are generally unknown in prostate cancer.

Evidence from preclinical human studies as well as in vitro and in vivo laboratory experiments emphasize the importance of naturally occurring agents in inhibiting cancer development and progression by downregulating the Wnt/ $\beta$-catenin signaling. ${ }^{5}$ It has been suggested that genistein enhanced GSK3 $\beta$ binding to $\beta$-catenin and increased $\beta$-catenin phosphorylation. ${ }^{10}$ It has also been suggested that genistein inactivates $\mathrm{Wnt} / \beta$-catenin signaling to initiate prostate cancer development. ${ }^{5}$ Genistein also decreased Wnt1-induced proliferation and the expression of Wnt target genes, including c-myc and cyclin D1. ${ }^{11,12}$ Curcumin also increased the degradation of cytoplasmic $\beta$-catenin, decreased nuclear $\beta$-catenin levels, and inhibited nuclear $\beta$-catenin/TCF transcriptional activity in cancer cells. ${ }^{13}$ Resveratrol has been shown to significantly inhibit the localization of $\beta$-catenin to the nucleus as well as decrease the phosphorylation of $\beta$-catenin in colon

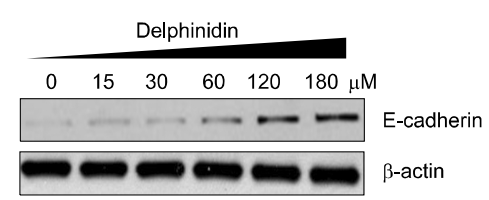

Figure 4. Effect of delphinidin on the expression of E-cadherin in PC3 cells. Cells were treated with specified concentrations of delphinidin for 72 hours and harvested, after which total cell lysates were prepared. Protein levels were evaluated by Western blotting for E-cadherin. Equal loading of proteins was confirmed by stripping the immunoblot and reprobing it for $\beta$-actin. The immunoblots shown here are representative of three independent experiments. 
cancer. ${ }^{14}$ In this study, we hypothesized that delphinidin is a potent dietary chemopreventive agent against prostate cancer. To test this hypothesis, we evaluated the efficacy of delphinidin as an anti-proliferative agent in human prostate cancer PC3 cells and further elucidated its mechanism of action, particularly in $\beta$-catenin signaling. Based on our results, delphinidin treatment of cells increased the phosphorylation of $\beta$-catenin at the serine and threonine residues and decreased the levels of cytoplasmic $\beta$-catenin. Furthermore, treatment of cells with delphinidin inhibited the nuclear translocation of $\beta$-catenin and suppressed the expression of cyclin D1, c-myc, Axin 2, and TCF1, which are downstream target genes of $\beta$-catenin. We further investigated the effect of delphinidin on the $\beta$-catenin destruction complex. Delphinidin treatment of cells induced the phosphorylation of GSK3 $\beta$ and the expression of APC and Axin proteins. Collectively, our results indicate that delphinidin effectively suppressed prostate cancer growth in PC3 cells, at least in part, by blocking $\beta$-catenin signaling, and that it can be developed as a new inhibitor of the $\beta$-catenin signaling pathway against human prostate cancer.

\section{ACKNOWLEDGMENTS}

This study was financially supported by Chonnam National University (2015-0613).

\section{CONFLICTS OF INTEREST}

No potential conflicts of interest were disclosed.

\section{REFERENCES}

1. Ting H, Deep G, Agarwal C, Agarwal R. The strategies to control prostate cancer by chemoprevention approaches. Mutat Res
2014:760:1-15.

2. Traka MH, Melchini A, Mithen RF. Sulforaphane and prostate cancer interception. Drug Discov Today 2014;19:1488-92.

3. Surh YJ. Cancer chemoprevention with dietary phytochemicals. Nat Rev Cancer 2003;3:768-80.

4. Takahashi-Yanaga F, Sasaguri T. The Wnt/beta-catenin signaling pathway as a target in drug discovery. J Pharmacol Sci 2007; 104:293-302

5. Tarapore RS, Siddiqui IA, Mukhtar H. Modulation of Wnt/B-catenin signaling pathway by bioactive food components. Carcinogenesis 2012;33:483-91.

6. Khan N, Afaq F, Mukhtar H. Cancer chemoprevention through dietary antioxidants: progress and promise. Antioxid Redox Signal 2008; 10:475-510.

7. Lim W, Jeong W, Song G. Delphinidin suppresses proliferation and migration of human ovarian clear cell carcinoma cells through blocking AKT and ERK1/2 MAPK signaling pathways. Mol Cell Endocrinol 2016;422:172-81.

8. Hafeez BB, Siddiqui IA, Asim M, Malik A, Afaq F, Adhami VM, et al. A dietary anthocyanidin delphinidin induces apoptosis of human prostate cancer PC3 cells in vitro and in vivo: involvement of nuclear factor-kappaB signaling. Cancer Res 2008;68:8564-72.

9. Ozawa M, Baribault H, Kemler R. The cytoplasmic domain of the cell adhesion molecule uvomorulin associates with three independent proteins structurally related in different species. EMBO J 1989;8:1711-7.

10. Sarkar FH, Li Y, Wang Z, Kong D. Cellular signaling perturbation by natural products. Cell Signal 2009:21:1541-7.

11. Li Y, Wang Z, Kong D, Li R, Sarkar SH, Sarkar FH. Regulation of Akt/FOXO3a/GSK-3beta/AR signaling network by isoflavone in prostate cancer cells. J Biol Chem 2008;283:27707-16.

12. Su Y, Simmen RC. Soy isoflavone genistein upregulates epithelial adhesion molecule E-cadherin expression and attenuates beta-catenin signaling in mammary epithelial cells. Carcinogenesis 2009:30:331-9.

13. Ryu MJ, Cho M, Song JY, Yun YS, Choi IW, Kim DE, et al. Natural derivatives of curcumin attenuate the $\mathrm{Wnt} /$ beta-catenin pathway through down-regulation of the transcriptional coactivator p300. Biochem Biophys Res Commun 2008;377:1304-8.

14. Hope C, Planutis K, Planutiene M, Moyer MP, Johal KS, Woo J, et al. Low concentrations of resveratrol inhibit Wnt signal throughput in colon-derived cells: implications for colon cancer prevention. Mol Nutr Food Res 2008;52 Suppl 1:S52-61. 